\title{
Behaviors and body weight of suckling piglets in different social environments
}

\author{
Joon-Ki Hong ${ }^{1}$, Ki-Hyun Kim', Hyun-Su Hwang ${ }^{2}$, Jae-Kang Lee², Tae-Kyung Eom², and Shin-Jae Rhim ${ }^{2, *}$
}

\author{
* Corresponding Author: Shin-Jae Rhim \\ Tel: +82-31-670-4842, Fax: +82-31-676-4842, \\ E-mail: sjhim@cau.ac.kr \\ 'Swine Science Division, National Institute of Animal \\ Science, Cheonan 31000, Korea \\ ${ }^{2}$ School of Bioresourceand Bioscience, Chung-Ang \\ University, Ansung 17546, Korea
}

Submitted Aug 31, 2016; Revised Oct 28, 2016; Accepted Nov 18, 2016
Objective: This study was conducted to characterize the behaviors and the body weight of suckling piglets in different social environments.

Methods: Two groups of sows and suckling piglets housed either in individual farrowing crates in separate pens $(1.8 \times 2.4 \mathrm{~m}$, the control group) or in groups of three sows with their piglets in farrowing crates in a large common enclosure $(5.4 \times 2.2 \mathrm{~m}$, the treatment group) were observed with the aid of video technology for 9 consecutive hours on days 1, 2, and 3, after mixing. Results: Suckling, agonistic, and elimination behaviors of suckling piglets were significantly higher in the control group than in the treatment group. Inactive behavior was higher in the treatment group than in the control group. Most of the effects of the social environment on the suckling piglets seem to be the result of large reductions in behaviors and body weight for piglets switching from high activity to low activity. Moreover, suckling behavior and birth body weight were highly correlated with body weight at the end of the test.

Conclusion: The social environment that resulted from mixing, thus, had significant effects on the behavior and body weight of suckling piglets, and behavioral characteristics, therefore, should be considered when making improvements to the husbandry and care methods used in swine production.

Keywords: Farrowing Crate; Mixing Suckling Piglets; Swine; Video Technology in Animal Welfare

\section{INTRODUCTION}

The behavioral characteristics of pigs are generally consistent over time and are formed when they are young piglets [1]. New born piglets are subjected to stress because of competition for access to the teats of sows. This competition is followed by the development of a social order during the first 2 weeks of lactation [2,3]. Piglets are variously housed for production in both indoor confinement systems and outdoor systems. Much scientific research has been done to determine the proper rearing conditions for the physical and psychological growth of the animals [4-6].

In response to changes in their environments, animals use behaviors to modify and control their surroundings [7,8]. Mixing different litters of piglets is common during the rearing process and results in environmental change and social stress $[9,10]$. However, mixing and sudden interruptions do not occur in wild boar populations in natural ecosystems [1]. The mixed piglets are exposed to harsh conditions with changed social and physical environments. Moreover, considerable stress is caused by the changes in diets, rearing conditions, housing, and neighbors that result from mixing [11,12]. The behavior of piglets following mixing is an animal welfare concern, and it has bearing on the search for husbandry and care methods that reduce stress [13,14]. High levels of stress and aggression from mixing can compromise pig welfare [15]. 
In South Korea, most piglets are bred and reared in farrowing crates (also known as sow stalls) within housing facilities. In general, the size of farrowing crates is $0.8 \times 2.0 \mathrm{~m}$ in pen $(1.8 \times 2.4$ $\mathrm{m})$. The floor is usually covered by concrete or plastic. There is feeder, drinker, and heat lamp in each pen. These provide safety to the piglets against fighting, injuring, or killing their fellow littermates, while at the same time minimizing various environmental and social challenges [16]. In addition, most piglets reared under this system have no chance to interact with different litters until weaning. There are also continuing controversies over the use of farrowing crates, especially with respect to their effect on the welfare of sows and piglets.

The pre-weaning experiences of piglets are understood to be important factors through their lives especially during the immediate post-weaning period [17]. Despite their relevance to growth performance and animal welfare of suckling piglets to the swine industry, there is relatively little known about suckling piglets. In this study, we examine the behavioral characteristics and body weight of suckling piglets in different social environments.

\section{MATERIALS AND METHODS}

The experiment was conducted at the experimental farm of the National Institute of Animal Science in Cheonan (Chungnam Province, South Korea) using 159 suckling piglets and 16 sows (Landrace $\times$ Yorkshire $\times$ Duroc). Sows and suckling piglets were reared in farrowing crates $(0.8 \times 2.0 \mathrm{~m})$ in pens $(1.8 \times 2.4 \mathrm{~m})$ with solid plastic flooring and a heat lamp. In sixteen pens, the sows and their piglets were reared in the farrowing crates for 10 days following the birth of piglets. The number of piglets ranged from 8 to 12 with a mean of 9.94 individuals/pen. Ten days after the birth of the piglets, the fences separating three of the pens were removed, and three sows and their piglets were reared together in this larger enclosure $(5.4 \times 2.2 \mathrm{~m}$, the treatment group). Because neonatal piglets are immunologically underdeveloped at birth [18], to minimize the mixing stress the piglets were mixed on day 10 after birth, which they have acquired the minimum immunity [19] and their suckling behavior has been stabilized [20].

In the treatment group, the three sows were still kept in separate farrowing crates and piglets could freely move in the large enclosure. In the control group, sows and their piglets were in a separate pen. The mean birth body weight of the piglets $2.21 \pm 0.53$ $\mathrm{kg}$ at day $10 \mathrm{after}$ the birth. There were no differences in starting point conditions of sows and suckling piglets between the groups in this study. The sows were the same year and similar body conditions. Moreover, the body conditions and weight of suckling piglets were not differed in starting points for the treatment and control group.

The environmental control systems were the same in all the housing facilities. The temperature in each pen was controlled by ventilation fans and heaters and was maintained at approximately $28^{\circ} \mathrm{C} \pm 1^{\circ} \mathrm{C}$. Each pen was provided with a stainless steel feeder and a nipple drinker that allowed the piglets ad libitum access to food and water throughout the experiment. The experimental protocols describing the management and care of the animals were reviewed and approved according to the Guide for the Care and Use of Laboratory Animals (National Institute of Animal Science, Animal Care Committee of Korea) on 7 March 2014 (approval number: NIAS 2014-289).

Four replicates each were evaluated in the control $(\mathrm{n}=4)$ and treatment $(\mathrm{n}=4)$ groups. Two wide-angle video cameras were installed at the corners of the ceiling, so that all the areas of the pen could be observed. The behaviors of the piglets were videorecorded continuously for 9 hours per day for 3 consecutive days. All behavioral data were obtained from video images that were digitally recorded from 09:00 to 18:00 $\mathrm{h}$ on days 1,2 , and 3 after mixing. Instantaneous scan sampling was carried out at 10-min intervals. All video recordings were viewed by trained observers who were blinded to the treatments to eliminate subjective bias and interindividual discrepancy [14,21].

The following behaviors were recorded: drinking, feeding, suckling, inactive, agonistic, locomotion, excretion, and other social behaviors (Table 1). The duration and frequency of the individual performing the behavior, as well as the individual receiving the behavior, was noted. The behavioral time values presented are the means and standard errors of the relative frequencies of each behavior, calculated from the results obtained from each observation of each group [12,22].

Data analysis was performed using SAS software (SAS Institute, Cary, NC, USA), with the pen serving as the experimental unit. The residual data sets were tested for normality using the Univariate Procedure of SAS [22]. The data were not normally distributed so the behavioral data were analyzed by a MannWhitney $\mathrm{U}$ test between the control and treatment groups. Correlations among behaviors and body weights were analyzed by a Kendall's Tau-b correlation, and $\mathrm{p}$ values were calculated.

\section{RESULTS}

There was no difference in body weight of suckling piglets in day

Table 1. Ethogram of behavioral categories and their respective definitions (adapted from Hwang et al [12]; Statham et al [31])

\begin{tabular}{|c|c|}
\hline Behavior & Description \\
\hline Drinking & $\begin{array}{l}\text { Drinking water or manipulating the drinker with or without inges- } \\
\text { tion of water }\end{array}$ \\
\hline Feeding & $\begin{array}{l}\text { Head positioned in the feeder or chewing food displaced from the } \\
\text { feeder }\end{array}$ \\
\hline Suckling & Massaging or suckling at sow's udder \\
\hline Inactive & Motionless and sleeping \\
\hline Agonistic & Biting, head-thrusting, ramming, or pushing another piglet \\
\hline Locomotion & $\begin{array}{l}\text { Any movement including walking, running, scampering, and } \\
\text { rolling }\end{array}$ \\
\hline Excretion & Defecating or urinating \\
\hline Other social & All other social behaviors not listed above \\
\hline
\end{tabular}


Table 2. Amount of time (second) of time spent per hour in different behaviors of suckling piglets in the control and treatment groups on days 1, 2, and 3 after mixing; comparisons between the control and treatment groups are based on a MannWhitney U test

\begin{tabular}{lccccccrr}
\hline \multirow{2}{*}{ Behavior } & \multicolumn{2}{c}{ Control } & & \multicolumn{2}{c}{ Treatment } & \multirow{2}{*}{ Z } & p value \\
\cline { 2 - 3 } & Mean & SE & & Mean & SE & & \\
\hline Drinking & 18.79 & 3.23 & & 23.64 & 3.24 & -0.26 & 0.80 \\
Feeding & 20.67 & 4.09 & & 16.44 & 3.26 & -1.92 & 0.06 \\
Suckling & $1,537.91$ & 60.40 & & 917.13 & 44.20 & -8.28 & $<0.01$ \\
Inactive & $1,520.38$ & 75.00 & & $2,093.95$ & 44.86 & -5.09 & $<0.01$ \\
Agonistic & 181.66 & 36.41 & & 8.16 & 1.44 & -6.90 & $<0.01$ \\
Locomotion & 180.96 & 9.38 & & 150.01 & 7.10 & -2.39 & 0.02 \\
Elimination & 66.16 & 9.11 & & 17.94 & 3.72 & -5.89 & $<0.01$ \\
Other social & 105.63 & 8.99 & & 71.59 & 6.11 & -3.51 & $<0.01$ \\
\hline
\end{tabular}

SE, standard error.

10 after the birth between the control and treatment groups $(\mathrm{Z}=$ $2.41, \mathrm{p}=0.57)$. However, the mean body weight at the end of the test was $8.78 \mathrm{~kg}$ in the control group and $8.07 \mathrm{~kg}$ in the treatment group. The end of the test body weight of piglets was significantly different between the two groups $(Z=-5.99, p<0.01)$.

The amount of time the piglets spent performing the different behaviors was significantly different between the control and treatment groups (Table 2). The durations of suckling (MannWhitney $U$ test, $Z=-8.28, \mathrm{p}<0.01)$, agonistic $(Z=-6.90, \mathrm{p}<0.01)$, locomotion $(Z=-2.39, p=0.02)$, elimination $(Z=-5.89, p<0.01)$, and other social behaviors $(Z=-3.51, \mathrm{p}<0.01)$ were higher in the control group than in the treatment group. The duration of inactive behavior $(Z=-5.09, p<0.01)$ was higher in the treatment
Table 3. Frequencies of different behaviors (incidents per hour) of suckling piglets in the control and treatment groups on days 1, 2, and 3 after mixing; comparisons between the control and treatment groups are based on a Mann-Whitney $U$ test

\begin{tabular}{lccccccrr}
\hline \multirow{2}{*}{ Behavior } & \multicolumn{2}{c}{ Control } & & \multicolumn{2}{c}{ Treatment } & \multirow{2}{*}{ Z } & p value \\
\cline { 2 - 3 } & Mean & SE & & Mean & SE & & \\
\hline Drinking & 1.52 & 0.26 & & 1.56 & 0.21 & -0.06 & 0.95 \\
Feeding & 1.46 & 0.26 & & 0.87 & 0.18 & -2.84 & $<0.01$ \\
Suckling & 21.20 & 1.09 & & 17.51 & 0.92 & -3.39 & $<0.01$ \\
Inactive & 49.71 & 1.84 & & 36.35 & 1.25 & -5.85 & $<0.01$ \\
Agonistic & 2.35 & 0.43 & & 0.86 & 0.18 & -3.64 & $<0.01$ \\
Locomotion & 27.99 & 1.47 & & 34.15 & 2.13 & -0.99 & 0.32 \\
Elimination & 2.59 & 0.33 & & 0.66 & 0.12 & -6.46 & $<0.01$ \\
Other social & 8.71 & 0.84 & & 8.86 & 0.76 & -1.47 & 0.14 \\
\hline
\end{tabular}

SE, standard error.

group. The amount of time spent in drinking and feeding did not differ between the two groups.

The frequencies of feeding $(Z=-2.84, p<0.01)$, suckling $(Z=$ $-3.39, \mathrm{p}<0.01)$, inactive $(Z=-5.85, \mathrm{p}<0.01)$, agonistic $(Z=-3.64$, $\mathrm{p}<0.01)$, and elimination behaviors $(Z=-6.46, \mathrm{p}<0.01)$ were significantly different between the control and treatment groups. Frequencies of those behaviors were higher in the control group than in the treatment group. There were no differences in the frequencies of drinking $(Z=-0.06, p=0.95)$, locomotion $(Z=$ $-0.99, \mathrm{p}=0.32)$, and other social behaviors $(\mathrm{Z}=-1.47, \mathrm{p}=0.14)$ between the control and treatments groups (Table 3 ).

There were significant correlations between the behaviors and body weights of the piglets in this study (Figure 1). Agonistic and locomotion behaviors were positive related to drinking (Kendall's

\begin{tabular}{|c|c|c|c|c|c|c|c|c|c|}
\hline Drinking & - & & & & & & & & \\
\hline Feeding & $\begin{array}{l}\mathrm{r}=0.15 \\
\mathrm{p}<0.01\end{array}$ & - & & & & & & & \\
\hline Suckling & & & - & & & & & & \\
\hline Inactive & $\begin{array}{c}\mathrm{r}=-2.10 \\
\mathrm{p}<0.01\end{array}$ & $\begin{array}{c}\mathrm{r}=-0.14 \\
\mathrm{p}<0.01\end{array}$ & $\begin{array}{c}\mathrm{r}=-0.20 \\
\mathrm{p}<0.01\end{array}$ & - & & & & & \\
\hline Agonistic & $\begin{array}{l}\mathrm{r}=0.24 \\
\mathrm{p}<0.01\end{array}$ & $\begin{array}{l}\mathrm{r}=0.15 \\
\mathrm{p}<0.01\end{array}$ & & $\begin{array}{c}\mathrm{r}=-0.32 \\
\mathrm{p}<0.01\end{array}$ & - & & & & \\
\hline Locomotion & $\begin{array}{l}\mathrm{r}=0.23 \\
\mathrm{p}<0.01\end{array}$ & $\begin{array}{l}\mathrm{r}=0.23 \\
\mathrm{p}<0.01\end{array}$ & & $\begin{array}{c}r=-0.34 \\
p<0.01\end{array}$ & & - & & & \\
\hline Elimination & $\begin{array}{l}r=0.09 \\
p=0.05\end{array}$ & & $\begin{array}{l}\mathrm{r}=0.20 \\
\mathrm{p}=0.01\end{array}$ & & & $\begin{array}{l}r=0.12 \\
p=0.01\end{array}$ & - & & \\
\hline Other social & $\begin{array}{l}\mathrm{r}=0.17 \\
\mathrm{p}<0.01\end{array}$ & $\begin{array}{l}\mathrm{r}=0.22 \\
\mathrm{p}<0.01\end{array}$ & & & $\begin{array}{c}\mathrm{r}=-0.16 \\
\mathrm{p}<0.01\end{array}$ & $\begin{array}{l}\mathrm{r}=0.36 \\
\mathrm{p}<0.01\end{array}$ & $\begin{array}{l}\mathrm{r}=0.23 \\
\mathrm{p}<0.01\end{array}$ & - & \\
\hline \multirow[t]{2}{*}{$\begin{array}{l}\text { End of test } \\
\text { body weight }\end{array}$} & & & $\begin{array}{l}\mathrm{r}=0.15 \\
\mathrm{p}<0.01\end{array}$ & & & & & & - \\
\hline & Drinking & Feeding & Suckling & Inactive & Agonistic & Locomotion & Elimination & Other social & $\begin{array}{l}\text { End of test } \\
\text { body weight }\end{array}$ \\
\hline
\end{tabular}

Figure 1. Correlation between duration of time spent in different behaviors and body weights of suckling piglets. 
Tau-b correlation, $\mathrm{r}=0.23$ to $0.24, \mathrm{p}<0.01)$ and feeding $(\mathrm{r}=0.15$ to $0.23, \mathrm{p}<0.01)$. Elimination was correlated to drinking $(\mathrm{r}=0.09$, $\mathrm{p}=0.05)$, suckling $(\mathrm{r}=0.20, \mathrm{p}=0.01)$, and locomotion $(\mathrm{r}=0.12$, $\mathrm{p}=0.01$ ). Inactivity was negatively correlated to drinking, feeding, and suckling behaviors because the piglets cannot be active and inactive at the same time. Moreover, there was positive relationship between dry matter intake (feeding) and drinking. Moreover, suckling behavior $(r=0.15, \mathrm{p}<0.01)$ was related to end-of-test body weight.

\section{DISCUSSION}

This study showed that mixing suckling piglets influenced their activity and body weight, but had no negative effects on their behavior. There were increases in suckling, locomotion, elimination, and other social behaviors, and the duration and frequency of inactive behaviors were dramatically increased by mixing. It should be recognized that the treatment groups in this study not only experienced interaction with unfamiliar sows and piglets, but also changes in the environment with increased space and more animals.

This study does identify a difference in agonistic behaviors between the two groups. It has been suggested that the agonistic behavior of suckling piglets could have some adaptive value for them [3]. Mixing post-weaned piglets from different litters is the major cause of aggressive behavior, which occurs during new hierarchy establishment $[23,24]$. However, the suckling piglets in the treatment groups showed less intense fighting and biting compared to the piglets in the control group. The mixing of the piglets led to less agonistic behavior in the treatment groups. Those results indicate that social stress and competition in the treatment group were not severe for the animals. Moreover, it had been reported that suckling piglets establish a hierarchy more quickly and show a shorter duration of aggression compared to weaned piglets when they are mixed $[24,25]$.

The increased inactive behavior and the decreased suckling, agonistic, locomotion, elimination, and other social behaviors in the treatment groups suggest that the piglets were depressed by mixing. Except for those changes, the piglets' overall activity values were high. In particular, suckling and feeding behaviors of piglets were higher in the control group. There was a higher body weight value in the control group at the end of the test than in the treatment group. It seemed that the low milk and feed intake of the piglets in the treatment group led to reduced growth or low weight gain in the first three days after mixing [26].

The behavioral characteristics of piglet littermates can produce large variations in their social status, growth performance, and survival $[27,28]$. The early social environment and experience of piglets is influential on the welfare and growth performance of pigs [29], and offspring exposed to early stress often exhibit behavioral difficulties later in life. The social environment may therefore play an important role in behavior and growth perfor- mance $[17,30]$. In addition, changes in the early social environment provide an opportunity for suckling piglets to learn social skills [8].

These results show that suckling piglets, when placed in a different social environment through mixing, exhibit changes in behavior and body weight. This suggests that the social environment of suckling piglets has significantly different effects on the behavior of the animals when they are reared in separate farrowing crates or mixed with other littermates in a large enclosure. Moreover, this mixing of suckling piglets will influence social behavior and welfare in the post-weaning period. The measurement of behavior and growth performance made in this study are insufficient to distinguish swine welfare and production, so further studies of piglets under additional rearing conditions are needed.

\section{CONFLICT OF INTEREST}

We certify that there is no conflict of interest with any financial organization regarding the material discussed in the manuscript.

\section{ACKNOWLEDGMENTS}

The authors would like to thank the technical assistants for their skilled work and the farm staff for animal care at the National Institute of Animal Science. This study was supported by the Agriculture Science and Technology Project (Grant Number: PJ009971) of the Rural Development Administration, Republic of Korea.

\section{REFERENCES}

1. Skok J, Škorjanc D. Fighting during suckling: Is it really an epiphenomenon? Ethology 2014;120:627-32.

2. Milligan BN, Fraser D, Kramer DL. Birth weight variation in the domestic pig: Effects on offspring survival, weight gain and suckling behavior. Appl Anim Behav Sci 2001;73:179-91.

3. Skok J, Škorjanc D. Formation of teat order and estimation of piglets' distribution along the mammary complex using mid-domain effect (MDE) model. Appl Anim Behav Sci 2013;144:39-45.

4. Newberry RC. Environmental enrichment: increasing the biological relevance of captive environments. Appl Anim Behav Sci 1995;44:229 -43 .

5. Hill JD, McGlone JJ, Fullwood SD, Miller MF. Environmental enrichment influences on pig behavior, performance and meat quality. Appl Anim Behav Sci 1988;57:51-68.

6. Kutzer T, Bünger B, Kjaer JB, Schrader L. Effects of early contact between non-littermate piglets and of the complexity of farrowing conditions on social behavior and weight gain. Appl Anim Behav Sci 2009;121:16-24.

7. Appleby MC, Hughes BO. Understanding animal welfare. Oxon, UK: CABI; 1997. 
8. Kanaan VT, Lay DC, Richert BT, Pajor EA. Increasing the frequency of co-mingling piglets during the lactation period alters the development of social behavior before and after weaning. J Appl Anim Wel Sci 2012;15:163-80.

9. Hayne SM, Gonyou HW. Behavioural uniformity or diversity? Effects on behavior and performance following regrouping in pigs. Appl Anim Behav Sci 2006;98:28-44.

10. Turner SP, Roehe R, D'Eath RB, et al. Genetic validation of postmixing skin injuries in pigs as an indicator of aggressiveness and the relationship with injuries under more stable social conditions. J Anim Sci 2009;87:3076-82.

11. Varley M, Wiseman J. The weaner pig. Oxford, UK: CABI; 2001.

12. Hwang HS, Lee JK, Eom TK, et al. Behavioral characteristics of weaned piglets mixed in different groups. Asian-Australas J Anim Sci 2016;29: 1060-4.

13. Broom DM. Animal welfare: concepts, study methods and indicators. Rev Colomb Cienc Pecu 2011;24:306-21.

14. Rhim SJ. Effects of group size on agonistic behaviors of commercially housed growing pigs. Rev Colomb Cienc Pec 2012;25:353-9.

15. Verdon M, Morrison RS, Hemsworth PH. Rearing piglets in multilitter group lactation systems: effects on piglet aggression and injuries post-weaning. Appl Anim Behav Sci 2016;183:35-41.

16. Benson GJ, Rollin BE. The well-being of farm animals: Challenges and solutions. Ames, IA: Blackwell Publishing; 2004.

17. Cox LN, Cooper JJ. Observations on the pre- and post-weaning behaviour of piglets reared in commercial indoor and outdoor environments. Anim Sci 2001;72:75-86.

18. Rookea JA, Bland IM. The acquisition of passive immunity in the new-born piglet. Livest Prod Sci 2002;78:13-23.

19. Kielland C, Rootwelt V, Reksen O, Framstad T. The association between immunoglobulin $\mathrm{G}$ in sow colostrum and piglet plasma. J Anim Sci 2015;93:4453-62.

20. Puppe B, Tuchscherer A. Developmental and territorial aspects of suckling behaviour in the domestic pig. J Zool 1999;249:307-13.
21. Li Y, Wang L. Effects of previous housing system on agonistic behaviors of growing pigs at mixing. Appl Anim Behav Sci 2011;132:20-6.

22. Rhim SJ, Son SH, Hwang HS, Lee JK, Hong JK. Effects of mixing on the aggressive behavior of commercially housed pigs. Asian-Australas J Anim Sci 2015;28:1038-43.

23. Jensen P. The ethology of domestic animals: an introductory text. Oxon, UK: CABI; 2002.

24. Hessel EF, Reiners K, Van den Weghe HFA. Socializing piglets before weaning: effects on behavior of lactating sows, pre- and postweaning behavior, and performance of piglets. J Anim Sci 2006;84:2847-55.

25. D'Eath RB. Socialising piglets before weaning improves social hierarchy formation when pigs are co-mingled post-weaning. Appl Anim Behav Sci 2005;93:199-211.

26. Oostindjer M, van den Brand H, Kemp B, Bolhuis JE. Effects of environmental enrichment and loose housing of lactating sows on piglet behavior before and after weaning. Appl Anim Behav Sci 2011;134: 31-41.

27. Houpt KA. Domestic animal behavior for veterinarians and animal scientists. Ames, IA: Blackwell Publishing; 1982.

28. Giroux S, Robert S, Martineau GP. The effects of cross-fostering on growth rate and post-weaning behavior of segregated early-weaned piglets. Can J Anim Sci 2000;80:533-8.

29. Skok J, Prevolink M, Urek T, Mesarec N, Škorjanc D. Behavioural patterns established during suckling reappear when piglets are forced to form a new dominance hierarchy. Appl Anim Behav Sci 2014;16: 42-50.

30. Veenema AH. Early life stress, the development of aggression and neuroendocrine and neurobiological correlates: what can we learn from animal models? Front Neuroendocrinol 2009;30:497-518.

31. Statham P, Green L, Bichard M, Mendl M. A longitudinal study of the effects of providing straw at different stages of life on tail-biting and other behavior in commercially housed pigs. Appl Anim Behav Sci $2011 ; 134: 100-8$. 